\title{
Decision-making approach by employing grey incidence analysis and group negotiation
}

\author{
LIU Yong", LI Jiao, and ZHANG Renshi
}

School of Business, Jiangnan University, Wuxi 214122, China

\begin{abstract}
For the problems of the consistency ranking of the group decision-making scheme, from the view of group negotiation and system coordination, the grey incidence analysis and Nash bargaining model are used to establish a consistency group decision-making method. First, the concepts of the consensus partial decision-making program and the consensus overall ideal decision-making program are defined, and then a multi-object optimization model is constructed based on the satisfaction maximization of group negotiation and deviation minimization of system coordination to determine the consensus partial decision-making program and the consensus overall ideal decision-making program. Moreover, the grey incidence analysis is exploited to measure the close degrees between them. Finally, a real case of the online product evaluation verifies the validity and rationality of the proposed model.
\end{abstract}

Keywords: group decision-making, group negotiation, system coordination, grey incidence analysis.

DOI: $10.21629 / J S E E .2019 .04 .13$

\section{Introduction}

Group decision-making problems exist widely in the social life. With the gradual depth and development of the democratization and scientific management, it is necessary to establish an effective method based on group decisionmaking and group negotiation to solve some decision making problems. As an effective method to deal with them, the group decision-making method plays a very important role in real living. It is the interdisciplinary subject of mathematics, politics, economics, management, behavioral science, social psychology and decision science. For

\footnotetext{
Manuscript received March 30, 2018.

*Corresponding author.

This work was supported by the National Natural Science Foundation of China (71503103), the Humanities and Social Sciences of Education Ministry (17YJC640233), the Jiangsu Province University Philosophy and Social Sciences for Key Research Program (2017ZDIXM034), the Soft Science Foundation of Jiangsu Province (BR2018005), the Natural Science Foundation of Jiangsu Province (BK20150157), the Fundamental Research Funds for the Central Universities (2019JDZD06) and the Key Soft Science Foundation of Wuxi (KX-18-B01).
}

group decision-making problems, according to their own knowledge and experience, decision-makers (DMs) evaluate the various index or the index set of the program. How to assemble the group decision-making information and reach consistent decision-making results becomes a hot issue in the decision science research.

At present, the group decision-making methods or models mainly focus on the processing of different index values (interval number, binary semantics, fuzzy number, intuitionistic fuzzy number, hesitation fuzzy number, etc.), the construction of aggregation operators and consistency measure indexes (weighted geometric operators, additive consistency, multiplication consistency, etc.), weight determination (DM weight, index weight), and the construction of the group heterozygous model based on different soft computing methods. In the process of actual group decision-making, due to the complexity and uncertainty of the objective world, the values are given in the form of the uncertain number such as the grey number [1], and some grey group decision-making models based on the grey incidence analysis and the group decision method are established to deal with these problems.

According to the existing literature on the application of group decision-making methods, there are mainly the following aspects. (i) The fuzzy number, fuzzy preference relationship and multi-attribute are applied to the group decision making method, and the decision ordering is obtained by the aggregation matrix [2-14]. These models and methods mainly solve the actual problems by determining the weights of DMs and using the iterative algorithm to solve the problem, but they cannot solve the problem of uncertain numbers in the real life. (ii) Through the research on the preference of DMs and the consistency of opinions of DMs, analyzing the influence of group attitudes on the process of consensus decision making of group decision [15-22]. These studies are based on the DMs themselves and analyze the process of reaching consensus. However, in the case of multiple 
DMs with multiple indicators and multiple programs, the consensus reached by these methods does not enable all DMs to achieve satisfactory results and meet psychological expectations. (iii) Some other methods use hierarchical clustering algorithms and integration operators to construct hybrid multi-criteria decision making methods and choose the best solution [23-31]. Although the complexity of decision-making is considered by multiple alternatives, and multiple methods are used to sort the alternatives, these methods does not consider the satisfaction of the DMs, and the decision-making results are one-side.

In order to better analyze the combination of group decision making problems and the grey theory, we collect the literature on the use of the grey theory and other group decision-making models, they are related to three aspects shown as follows. (i) As a data preprocessing method, the grey incidence analysis method is used to construct some heterozygous models by combining with decisionmaking models [32-36]. These models only hybrid the grey incidence analysis method and other group decisionmaking models, and do not effectively extract and deal with the group decision-making information especially the uncertain information, so that they easily generate information distortion in the process of information gathering. (ii) Some optimization models based on the grey incidence analysis are constructed to solve the weights of the indexes and the DMs [37-39]. Although these models can solve the agglomeration problems of group decisionmaking, they do not effectively excavate and extract decision information and objectively give the setting mechanism of the ideal reference sequence, and then they often result in information distortions. (iii) Considering that the group decision-making index values take on the form of the binary semantics $[40,41]$, linguistic $[38,42]$, intuitionist fuzzy [37], interval grey number [39,43], some grey decision-making models with different kinds of the evaluation values are established to effectively assemble the decision-making information, however these methods are difficult to effectively excavate and extract the DM information and index information.

Based on the above discussion, the existing group decision-making methods could solve the weights of the index, DM, and time. However, they rarely consider the group behavior, so that it is difficult for them to fully excavate the group decision-making information and correctly rank the programs. In order to deal with the problems, from the view of the decision-making partial and overall consultation and system coordination, we establish an approach based on the grey incidence analysis and group negotiation.

The remainder of this paper is organized as follows. In Section 2, we firstly describe the general group decision problem, then, we construct two multi-objective optimization models by using the idea of the group decision and grey incidence analysis method. Finally, we use the grey incidence analysis method to construct the group decision scheme ranking method. The case of e-commerce platform commodity evaluation ranking is used to verify the validity and rationality of the constructed model in Section 3, and we compare it with the group decision ranking method proposed by other scholars. Section 4 concludes the paper.

\section{Multi-index decision approach}

Group decision problems mainly consist of four basic elements, programs, DMs, indexes and decision-making values, and the group consensus decision-making is based on information aggregation to determine the program ranking. Generally speaking, the indexes and programs influence decision-making results through the decision-making information, while DMs influence their results through their group game negotiation. To solve this, comprehensively considering the influence and role of the group decision information and behavior on the results, through group negotiation and system coordination, a multi-object optimization model is established to determine the consensus partial decision-making program and the consensus overall ideal decision-making program.

\subsection{Problem description}

Suppose that there exist a multi-index decision-making question denoted as a set of $\boldsymbol{G}=\{\boldsymbol{X}, \boldsymbol{A}, \boldsymbol{E}, \boldsymbol{V}\}$, in which $\boldsymbol{X}=\left\{\boldsymbol{x}_{1}, \ldots, \boldsymbol{x}_{i}, \ldots, \boldsymbol{x}_{n}\right\}, \boldsymbol{A}=\left\{\boldsymbol{a}_{1}, \ldots, \boldsymbol{a}_{j}, \ldots, \boldsymbol{a}_{m}\right\}$ and $\boldsymbol{E}=\left\{\boldsymbol{e}_{1}, \ldots, \boldsymbol{e}_{k}, \ldots, \boldsymbol{e}_{p}\right\}$ stand for the programs, indexes and DMs, respectively; and $\boldsymbol{V}=\cup v_{i j}^{k}(i=$ $1,2, \ldots, n ; j=1,2, \ldots, m ; k=1,2, \ldots, p)$ is the evaluation value range of the DMs under the multi-index, where $\boldsymbol{v}_{i j}^{k}$ is the evaluation value of the DM $e_{k}$ over the program $\boldsymbol{x}_{i}$ under the index $\boldsymbol{a}_{j}$; and $\boldsymbol{w}=\left(w_{1}, \ldots, w_{j}, \ldots, w_{m}\right)$ is the index weight vector, $\boldsymbol{\eta}=\left(\eta_{1}, \ldots, \eta_{k}, \ldots, \eta_{p}\right)$ is the weight vector of the DMs, and satisfies $0 \leqslant w_{j} \leqslant 1$, $\sum_{j=1}^{m} w_{j}=1,0 \leqslant \eta_{k} \leqslant 1, \sum_{k=1}^{p} \eta_{k}=1$.

Due to the complexity and variability of the objective world, and the differences and limitations of the subjective cognition of human beings, the multi-index group decision-making problem often has a variety of uncertain information. In order to deal with such problems, we utilize the grey incidence analysis to construct a consensus decision-making approach. For any decision-making program $\boldsymbol{x}_{i}$, there exists a consistent measure value vector or matrix produced by DMs with different indexes, which results from the group game negotiation. For the program set $\boldsymbol{X}$, there is also a consensus program after group game ne- 
gotiations. Correspondingly, the concepts of the consensus partial decision program and the consensus overall ideal decision program can be defined, respectively.

Definition 1 Assume that $\boldsymbol{u}_{i j}^{k}$ stands for the standardized measure value of the evaluation value $\boldsymbol{v}_{i j}^{k}$, for $\forall \boldsymbol{x}_{i} \in \boldsymbol{X}, \forall \boldsymbol{a}_{j} \in \boldsymbol{A}, \forall \boldsymbol{e}_{k} \in \boldsymbol{E}$, if $\boldsymbol{u}_{i j}^{*}$ and $\boldsymbol{u}_{0 j}^{*}$ are the consensus partial measure value and consensus overall ideal measure value under the index $\boldsymbol{a}_{j}$, respectively, then

$$
\begin{aligned}
\boldsymbol{x}_{i}^{*} & =\left\{\boldsymbol{u}_{i 1}^{*}, \ldots, \boldsymbol{u}_{i j}^{*}, \ldots, \boldsymbol{u}_{i m}^{*}\right\} \\
\boldsymbol{x}_{0}^{*} & =\left\{\boldsymbol{u}_{01}^{*}, \ldots, \boldsymbol{u}_{0 j}^{*}, \ldots, \boldsymbol{u}_{0 m}^{*}\right\}
\end{aligned}
$$

are called as the consensus partial decision-making program of $\boldsymbol{x}_{i}$ and the consensus overall ideal decision program of decision program set $\boldsymbol{X}$, respectively.

Definition 2 For $\forall \boldsymbol{x}_{i} \in \boldsymbol{X}, \forall \boldsymbol{a}_{j} \in \boldsymbol{A}, \forall \boldsymbol{e}_{k} \in \boldsymbol{E}$, $\boldsymbol{x}_{i}^{*}=\left\{\boldsymbol{u}_{i 1}^{*}, \ldots, \boldsymbol{u}_{i j}^{*}, \ldots, \boldsymbol{u}_{i m}^{*}\right\}$ and $\boldsymbol{x}_{0}^{*}=\left\{\boldsymbol{u}_{01}^{*}, \ldots\right.$, $\left.\boldsymbol{u}_{0 j}^{*}, \ldots, \boldsymbol{u}_{0 m}^{*}\right\}$, then the matrixes

$$
\begin{aligned}
& \boldsymbol{U}_{i}^{k}= {\left[\begin{array}{ccccc}
\boldsymbol{u}_{i 1}^{1} & \ldots & \boldsymbol{u}_{i j}^{1} & \ldots & \boldsymbol{u}_{i m}^{1} \\
\vdots & \ddots & \vdots & \ddots & \vdots \\
\boldsymbol{u}_{i 1}^{k} & \ldots & \boldsymbol{u}_{i j}^{k} & \ldots & \boldsymbol{u}_{i m}^{k} \\
\vdots & \ddots & \vdots & \ddots & \vdots \\
\boldsymbol{u}_{i 1}^{p} & \ldots & \boldsymbol{u}_{i j}^{p} & \ldots & \boldsymbol{u}_{i m}^{p}
\end{array}\right] } \\
& \boldsymbol{U}_{i}^{*}= {\left[\begin{array}{ccccc}
\boldsymbol{u}_{01}^{1} & \ldots & \boldsymbol{u}_{0 j}^{1} & \ldots & \boldsymbol{u}_{0 m}^{1} \\
\vdots & \ddots & \vdots & \ddots & \vdots \\
\boldsymbol{u}_{01}^{k} & \ldots & \boldsymbol{u}_{0 j}^{k} & \ldots & \boldsymbol{u}_{0 m}^{k} \\
\vdots & \ddots & \vdots & \ddots & \vdots \\
\boldsymbol{u}_{01}^{p} & \ldots & \boldsymbol{u}_{0 j}^{p} & \ldots & \boldsymbol{u}_{0 m}^{p}
\end{array}\right] } \\
& \boldsymbol{U}_{0}=\left[\begin{array}{ccccc}
\boldsymbol{u}_{01}^{*} & \ldots & \boldsymbol{u}_{0 j}^{*} & \ldots & \boldsymbol{u}_{0 m}^{*} \\
\vdots & \ddots & \vdots & \ddots & \vdots \\
\boldsymbol{u}_{01}^{*} & \ldots & \boldsymbol{u}_{0 j}^{*} & \ldots & \boldsymbol{u}_{0 m}^{*} \\
\vdots & \ddots & \vdots & \ddots & \vdots \\
\boldsymbol{u}_{01}^{*} & \ldots & \boldsymbol{u}_{0 j}^{*} & \ldots & \boldsymbol{u}_{0 m}^{*}
\end{array}\right]
\end{aligned}
$$

are called as the decision-making information matrix of the $\mathrm{DM} \boldsymbol{e}_{k}$, the measure matrix of the consensus partial decision program and the overall ideal decision program, respectively.

\subsection{Group decision approach for decision-making program by employing group negotiation and system coordination}

For group decision, the result is often produced by the group negotiation and system coordination. Generally speaking, through the game negotiation with different bargaining powers, consensus schemes can be determined, but all negotiation schemes are not accepted by all DMs, and there only exit few schemes, which are consensus schemes. In order to realize the stability and effectiveness of the system, the coordinator takes some measures to induce DMs to change their schemes in the system, and generate a consensus scheme. For group decision-making, DMs' weights are often used to express their bargaining powers. Assume that $\eta_{k}$ stands for the weight of the DM $\boldsymbol{e}_{k}$, and $\sum_{k=1}^{p} \eta_{k}=1$.

For the consensus partial decision-making program $\boldsymbol{x}_{i}^{*}$, assume that $\boldsymbol{u}_{i j}^{* k}$ expresses the negotiation strategy of the DM $\boldsymbol{e}_{k}$ after the group negotiation over the index $\boldsymbol{a}_{j}$, and $\boldsymbol{u}_{i j}^{*}$ stands for the consensus strategy of DMs after the decision-making system coordination over the index $\boldsymbol{a}_{j}$, each DM has a psychological expectation interval for all programs under the index $\boldsymbol{a}_{j}$, whose minimum and maximization psychological expectations can be denoted as $d_{1 i j}^{k}$ and $d_{2 i j}^{k}$, respectively. Generally speaking, the greater the value, the higher the DM's satisfaction degree. Let the ratio $\frac{d_{1 i j}^{k}}{d_{2 i j}^{k}}$ express the DM's satisfaction degree. Accordingly, the minimum satisfaction degree is the beginning point for the DM $e_{k}$ to negotiate. The greater the satisfaction degree, the more stable the system. However, as a result of the resource capability constraints, the DMs' ideal values are constrained by the total amount of the decision system resources. We take $\sum_{k=1}^{p} d_{2 i j}^{k}$ as the decision system resource. Let $\rho$ be the system bear coefficient of the decision-making system over any index $\boldsymbol{a}_{j}$, and it satisfies

$$
\operatorname{Max}_{j}\left\{\frac{\sum_{k=1}^{p} d_{1 i j}^{k}}{\sum_{k=1}^{p} d_{2 i j}^{k}}\right\}<\rho<1 .
$$

According to the above analysis, a relatively satisfactory result by maximizing the satisfaction deviation between the satisfactory and the minimum satisfaction can be obtained, so that we can construct an optimization model to solve the negotiation strategy of the DM $e_{k}$. In order to obtain a consensus strategy, the coordinator needs to carry out some coordination measures (such as the minimum deviation between group schemes and consensus schemes) to generate a consensus strategy for DMs and the consensus partial decision-making program $\boldsymbol{x}_{i}^{*}$. To determine the consensus partial decision program, we can establish a two-step optimization model shown as follows:

$$
\begin{aligned}
& \operatorname{Max} S=\sum_{j=1}^{m} w_{j} \prod_{k=1}^{p}\left(\frac{u_{i j}^{* k}}{d_{2 i j}^{k}}-\frac{d_{1 i j}^{k}}{d_{2 i j}^{k}}\right)^{\eta_{k}} \\
& \operatorname{Min} D=\sum_{j=1}^{m} w_{j} \sum_{k=1}^{p} \eta_{k}\left(u_{i j}^{*}-u_{i j}^{* k}\right)^{2}
\end{aligned}
$$




$$
\text { s.t. }\left\{\begin{array}{l}
d_{1 i j}^{k} \leqslant u_{i j}^{* k} \leqslant d_{2 i j}^{k} \\
\sum_{k=1}^{p} u_{i j}^{* k}=\rho \sum_{k=1}^{p} d_{2 i j}^{k} \\
d_{1 i j}^{k}=\underset{i}{k}\left\{u_{i j}^{k}\right\} \\
d_{2 i j}^{k}=\operatorname{Max}_{i}\left\{u_{i j}^{k}\right\} \\
\sum_{k=1}^{p} \eta_{k}=1 \\
\sum_{j=1}^{m} w_{j}=1 \\
\operatorname{Max}_{j}\left\{\begin{array}{l}
\sum_{k=1}^{p} d_{1 i j}^{k} \\
\sum_{k=1}^{p} d_{2 i j}^{k}
\end{array}\right\}<\rho<1 \\
i=1,2, \ldots, n ; j=1,2, \ldots, m ; \\
k=1,2, \ldots, p
\end{array}\right.
$$

Theorem 1 Model (1) has an optimal solution.

Proof Model (1) is a two-stage single-objective programming problem. According to the objective function and the actual meaning of each constraint and the existence theorem of the optimal solution [44], the model has an optimal solution. For the function of Max $S$, from the restriction $u_{i j}^{* k} \leqslant d_{2 i j}^{k}$, we have $\frac{u_{i j}^{* k}}{d_{2 i j}^{k}}-\frac{d_{1 i j}^{k}}{d_{2 i j}^{k}} \leqslant \frac{d_{2 i j}^{k}}{d_{2 i j}^{k}}-\frac{d_{1 i j}^{k}}{d_{2 i j}^{k}}=$ $1-\frac{d_{1 i j}^{k}}{d_{2 i j}^{k}}<1$, and then we obtain

$$
\begin{gathered}
\prod_{k=1}^{p}\left(\frac{u_{i j}^{* k}}{d_{2 i j}^{k}}-\frac{d_{1 i j}^{k}}{d_{2 i j}^{k}}\right)^{\eta_{k}} \leqslant\left[\left(1-\frac{d_{1 i j}^{1}}{d_{2 i j}^{1}}\right)^{\eta_{1}} \cdots\right. \\
\left.\left(1-\frac{d_{1 i j}^{k}}{d_{2 i j}^{k}}\right)^{\eta_{k}} \cdots\left(1-\frac{d_{1 i j}^{p}}{d_{2 i j}^{p}}\right)^{\eta_{p}}\right]< \\
{\left[1^{\eta_{1}} \cdots 1^{\eta_{k}} \cdots 1^{\eta_{p}}\right]=1^{\sum_{k=1}^{p} \eta_{k}}=1,}
\end{gathered}
$$

so that we have

$$
\sum_{j=1}^{m} w_{j} \prod_{k=1}^{p}\left(\frac{u_{i j}^{* k}}{d_{2 i j}^{k}}-\frac{d_{1 i j}^{k}}{d_{2 i j}^{k}}\right)^{\eta_{k}}<\sum_{j=1}^{m} w_{j}=1,
$$

thus the single-objective Max $S$ is convergent, that is $\operatorname{Max} S \rightarrow 1$. For the function of Min $D$, it is the minimum deviation between group decision-making schemes and consensus schemes, $\boldsymbol{u}_{i j}^{*}$ changes with $\boldsymbol{u}_{i j}^{* k}$, Min $D \rightarrow 0$.

Based on the above optimization model, the consensus partial decision-making program can be obtained as $\boldsymbol{x}_{i}^{*}=\left\{\boldsymbol{u}_{i 1}^{*}, \ldots, \boldsymbol{u}_{i j}^{*}, \ldots, \boldsymbol{u}_{i m}^{*}\right\}$, and the measure matrix of the consensus partial decision-making program is determined.

For the consensus overall decision-making program $\boldsymbol{x}_{0}^{*}=\left\{\boldsymbol{u}_{01}^{*}, \ldots, \boldsymbol{u}_{0 j}^{*}, \ldots, \boldsymbol{u}_{0 m}^{*}\right\}$, consider that each DM has a minimum and most willing to accept the evaluation value for each of the programs under the index, set as $d_{1 i j}^{k}, d_{2 i j}^{k}$, respectively, each DM has a minimum and most willing assessment of all the options under the index $\boldsymbol{a}_{j}$, which can be denoted as $d_{10 j}^{0 k}, d_{20 j}^{0 k}$, respectively, where, $d_{10 j}^{0 k}=\min _{i} d_{1 i j}^{k}, d_{20 j}^{0 k}=\max _{i} d_{2 i j}^{k}$. Similar to the process of the consensus partial decision-making program, considering the objective conditions of the decision-making system, such as resource capacity and other constraints, all DMs under different indexes are limited to determine their own ideal value of the decision-making system by the total amount of resources. Let $\rho$ be the system bear coefficient of the decision-making system over any index $\boldsymbol{a}_{j}$, and the DMs' decision-making function is generally taken as $\sum_{k=1}^{p} d_{2 i j}^{k}$, and $\operatorname{Max}_{j}\left\{\frac{\sum_{k=1}^{p} d_{1 i j}^{k}}{\sum_{k=1}^{p} d_{2 i j}^{k}}\right\}<\rho<1$, we can construct a multi-objective optimization model from the perspective of group negotiation and system coordination, whose expression is written as follows:

$$
\begin{gathered}
\operatorname{Max} S=\sum_{j=1}^{m} w_{j} \prod_{k=1}^{p}\left(\frac{u_{0 j}^{k}}{d_{20 j}^{k}}-\frac{d_{10 j}^{k}}{d_{20 j}^{k}}\right)^{\eta_{k}} \\
\operatorname{Min} D=\sum_{j=1}^{m} w_{j} \sum_{k=1}^{p} \eta_{k}\left(u_{0 j}^{*}-u_{0 j}^{k}\right)^{2} \\
\text { s.t. }\left\{\begin{array}{l}
d_{10 j}^{k} \leqslant u_{0 j}^{k} \leqslant d_{20 j}^{k} \\
\sum_{k=1}^{p} u_{0 j}^{k}=\rho \sum_{k=1}^{p} d_{20 j}^{k} \\
d_{10 j}^{k}=\operatorname{Min}_{i}\left\{d_{1 i j}^{k}\right\} \\
d_{20 j}^{k}=\operatorname{Max}_{i}^{k}\left\{d_{2 i j}^{k}\right\} \\
\sum_{k=1}^{p} \eta_{k}=1 \\
\sum_{j=1}^{m} w_{j}=1 \\
\operatorname{Max}_{j}\left\{\begin{array}{l}
\sum_{k=1}^{p} d_{1 i j}^{k} \\
\sum_{k=1}^{p} d_{2 i j}^{k}
\end{array}\right\}<\rho<1 \\
i=1,2, \ldots, n ; j=1,2, \ldots, m ; \\
k=1,2, \ldots, p
\end{array} .\right.
\end{gathered}
$$

Theorem 2 Model (2) must have an optimal solution.

Proof The model is a two-step single-objective programming problem, and the proof process is the same as Theorem 1. 
Based on the above optimization model, we can obtain the consensus overall ideal decision-making program $\boldsymbol{x}_{0}^{*}=\left\{\boldsymbol{u}_{01}^{*}, \ldots, \boldsymbol{u}_{0 j}^{*}, \ldots, \boldsymbol{u}_{0 m}^{*}\right\}$, and determine the measure matrix of the consensus overall ideal decision-making program.

\subsection{Ranking method for decision-making program based on grey incidence analysis}

According the Definition $1, \boldsymbol{x}_{0}^{*}$ is a relatively ideal program for the DMs to accept, and $\boldsymbol{x}_{i}^{*}$ can be used to measure the program $\boldsymbol{x}_{i}$. If the consensus partial decision-making program $\boldsymbol{x}_{i}^{*}$ is closer to the consensus overall decisionmaking program $\boldsymbol{x}_{0}^{*}$, then the program $\boldsymbol{x}_{i}$ is much better, vice versa. Consider that the grey incidence analysis method is based on the sequence curve geometry to determine whether the links between different sequences are close, which can measure the association of two sequences well. We utilize the grey incidence analysis to measure the proximity between the consensus partial decision-making program $\boldsymbol{x}_{i}^{*}$ and the consensus overall ideal program $\boldsymbol{x}_{0}^{*}$.

Definition 3 Suppose that $\boldsymbol{x}_{i}^{*}=\left\{\boldsymbol{u}_{i 1}^{*}, \ldots, \boldsymbol{u}_{i j}^{*}, \ldots\right.$, $\left.\boldsymbol{u}_{i m}^{*}\right\}, \boldsymbol{x}_{0}^{*}=\left\{\boldsymbol{u}_{01}^{*}, \ldots, \boldsymbol{u}_{0 j}^{*}, \ldots, \boldsymbol{u}_{0 m}^{*}\right\}$ are the consensus partial decision-making program and the consensus overall ideal decision-making program, respectively.

$$
\begin{gathered}
\boldsymbol{\xi}\left(\boldsymbol{u}_{0 j}^{*}, \boldsymbol{u}_{i j}^{*}\right)= \\
\frac{\min _{i} \min _{j} \boldsymbol{d}\left(\boldsymbol{u}_{0 j}^{*}, \boldsymbol{u}_{i j}^{*}\right)+\lambda \max _{i} \max _{j} \boldsymbol{d}\left(\boldsymbol{u}_{0 j}^{*}, \boldsymbol{u}_{i j}^{*}\right)}{\boldsymbol{d}\left(\boldsymbol{u}_{0 j}^{*}, \boldsymbol{u}_{i j}^{*}\right)+\lambda \max _{i} \max _{j} \boldsymbol{d}\left(\boldsymbol{u}_{0 j}^{*}, \boldsymbol{u}_{i j}^{*}\right)} \\
\boldsymbol{\xi}_{i}=\sum_{j=1}^{m} w_{j} \boldsymbol{\xi}\left(\boldsymbol{u}_{0 j}^{*}, \boldsymbol{u}_{i j}^{*}\right)
\end{gathered}
$$

are called as the grey incidence coefficient and degree between the consensus partial program $\boldsymbol{x}_{i}^{*}$ and the overall ideal decision-making program $\boldsymbol{x}_{0}^{*}$ over the index $\boldsymbol{a}_{j}$ and the index set $\boldsymbol{A}$, respectively. $\lambda$ is the resolution coefficient, and it is taken as 0.5 .

\subsection{Steps of the group decision-making approach}

According to the decision process, we can give the steps of the proposed group decision model in Fig. 1.

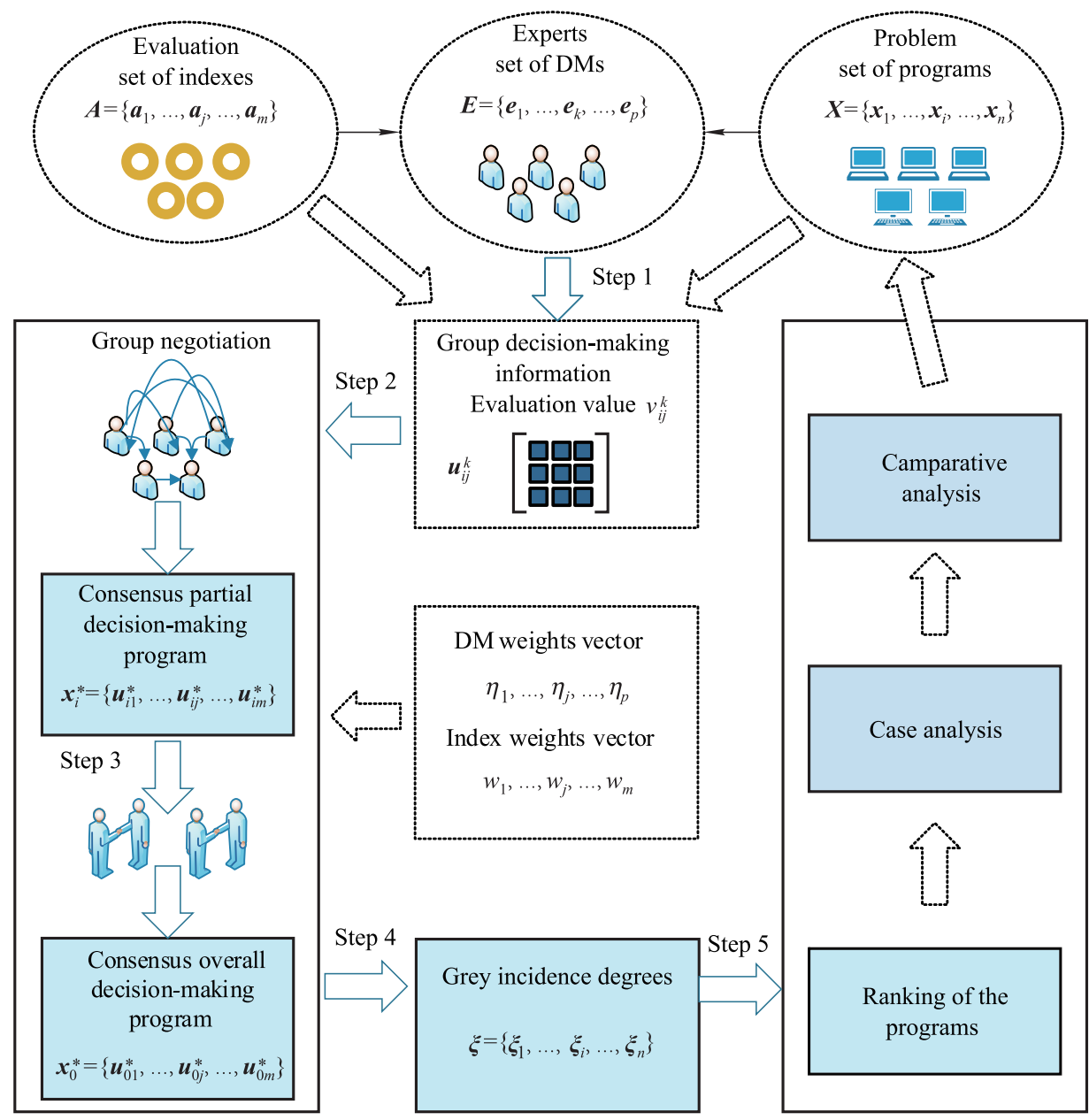

Fig. 1 Decision-making process 
Step 1 Collect and sort the group decision-making information, and standardize the evaluation value $\boldsymbol{v}_{i j}^{k}$.

Step 2 According to the standardized measure values, construct the multi-object optimization model based on the satisfaction maximization of group negotiation and the deviation minimization of system coordination to determine the consensus partial decision-making program.

Step 3 According to the standardized measure values, similar to the Step 2, construct the multi-object optimization model to compute the consensus overall ideal decision-making program.

Step 4 By exploiting (3) and (4), calculate the grey incidence coefficient and incidence degree between the partial consensus program $\boldsymbol{x}_{i}^{*}$ and the overall consensus ideal decision-making program $x_{0}^{*}$ over the index $\boldsymbol{a}_{j}$ and the index set $\boldsymbol{A}$.

Step 5 Based on the grey incidence degrees of the decision-making program, give the program ranking.

\section{Case analysis}

With the rapid development of the electronic market and e-commerce, online products are increasingly popular and widely used. There are some data showing that the major e-commerce mall provides super-billion of products on the market every year. On Taobao, for example, its registered users in 2010 reach 370 million, the number of online products reaches 800 million, an average of visitors is more than 60 million people a day, about 48000 items are sold per minute, and its single-day trading volume is more than 2 billion (except in recent years, the hundreds of billions of transactions in "Double 11 shopping carnival"). In recent years, with the development of the internet economy, the number of online products grows rapidly, there are an increasing number of registered users, and consumers may face some difficulties with the complex online products. Firstly, the users need to spend a lot of time to browse the site to compare the advantages and disadvantages of the products and make a choice with the large number of online products. Secondly, it is difficult for the users to make a direct contact and a detailed understanding with the virtual network products. Thirdly, in order to obtain considerable sales, the business may provide users with some unreal information, and these problems make it difficult for consumers to accurately and quickly get the desirable products. At present, in the purchase of online products, many consumers tend to consider the sales rankings, price rankings, credit rankings and other information on the shopping site to choose, and these ranking information provided by the shopping site is an approach to evaluate online products based on the performance of the products, which is likely to make businesses create false information. The site uses this information to rank the situation mistakenly, the interests of consumers are invisibly damaged, so an objective online product evaluation approach can effectively resist the trade fraud and help consumers make accurate purchase decisions.

At present, the online e-commerce evaluation approaches are the cumulative method, the average method, the probability method, the fuzzy method, the process method, et al. These methods all assume that the consumers have the same subjective preference and the evaluation criterion, however, because of different consumption psychologies and consumer backgrounds, the product scores consumers give are biased, some tend to higher the overall score, and some tend to lower the overall score, which led to the fact that evaluations of different consumers on the same products in fact do not have comparability. In this way, even the same performance of products will be given different scores, and the existing evaluation methods will make these properties of the same products get different evaluation results. Moreover, the performance of different products may also get the same score, the existing methods will make the performance of different products get the same evaluation results. Therefore, the evaluation results obtained by using the existing evaluation methods are not comparable and cannot objectively and accurately reflect the performance of the products, and the existing methods are highly operational and require only a high rating (or low score), one can achieve the purpose of manipulating the products, but the interests of consumers are harmed gravely. It is possible to establish a comparatively objective evaluation mechanism by fully considering the relationship between different users' voting and different products, which need an effective decision-making method to evaluate them. In view of this, we utilize the proposed model to analyze the problems.

\subsection{Program ranking based on the proposed model}

We choose the indexes of price, sales, performance, appearance and user evaluation to carry out the computer evaluation ranking analysis, which are recorded as $\boldsymbol{A}=\left\{\boldsymbol{a}_{1}, \boldsymbol{a}_{2}, \boldsymbol{a}_{3}, \boldsymbol{a}_{4}, \boldsymbol{a}_{5}\right\}$, respectively. An electric business platform through the sales, performance, user evaluation and other indexes of a comprehensive investigation and analysis to determine Lenovo, Asus, Dell, Acer, Apple and HP as the ranking analysis objects, they are recorded as $\boldsymbol{X}=\left\{\boldsymbol{x}_{1}, \boldsymbol{x}_{2}, \boldsymbol{x}_{3}, \boldsymbol{x}_{4}, \boldsymbol{x}_{5}, \boldsymbol{x}_{6}\right\}$, respectively; and five decision makers of the computer field are invited to evaluate, they are recorded as $\boldsymbol{E}=$ $\left\{\boldsymbol{e}_{1}, \boldsymbol{e}_{2}, \boldsymbol{e}_{3}, \boldsymbol{e}_{4}, \boldsymbol{e}_{5}\right\}$. Depending on the importance of the DMs and the authority of the field, the weights can be 
determined as $\boldsymbol{\eta}=(0.18,0.21,0.23,0.25,0.13)$, and the weights of the indexes are determined as $\boldsymbol{w}=$ $(0.23,0.15,0.30,0.14,0.18)$. In order to provide consumers with more accurate and more reasonable product rankings, the business platform allows the invited experts to set the price of the computers sold by the computer brands and vendors in the platform provided by the vendors and the price of different brands of the same brand, different brands similar to the type of computer prices, sales, appearance, performance and user evaluation and other in- formation, to determine the six brands to assess. Because of the limitation of experts' cognition and the complexity of the objective world, the experts' evaluation of each brand product under different indexes has a certain degree of greyness and ambiguity, thus the evaluation value is often given in the form of the interval grey number. By collecting and sorting the evaluation information of experts on different products and standardizing them, the decision information matrix of each DM can be described as follows:

$$
\begin{aligned}
& \boldsymbol{u}_{i j}^{1}=\left(\begin{array}{llllll}
{[0.71,0.79]} & {[0.85,0.89]} & {[0.84,0.90]} & {[0.78,0.82]} & {[0.79,0.86]} \\
{[0.75,0.83]} & {[0.80,0.83]} & {[0.70,0.75]} & {[0.71,0.76]} & {[0.78,0.83]} \\
{[0.69,0.73]} & {[0.68,0.79]} & {[0.79,0.83]} & {[0.72,0.76]} & {[0.73,0.77]} \\
{[0.68,0.74]} & {[0.66,0.69]} & {[0.71,0.75]} & {[0.64,0.68]} & {[0.67,0.73]} \\
{[0.65,0.73]} & {[0.69,0.76]} & {[0.89,0.92]} & {[0.82,0.89]} & {[0.81,0.84]} \\
{[0.69,0.77]} & {[0.65,0.69]} & {[0.72,0.76]} & {[0.78,0.83]} & {[0.79,0.84]}
\end{array}\right) \\
& \boldsymbol{u}_{i j}^{2}=\left(\begin{array}{llllll}
{[0.73,0.79]} & {[0.83,0.88]} & {[0.83,0.87]} & {[0.75,0.80]} & {[0.78,0.83]} \\
{[0.71,0.79]} & {[0.79,0.82]} & {[0.69,0.73]} & {[0.73,0.77]} & {[0.75,0.81]} \\
{[0.67,0.71]} & {[0.75,0.81]} & {[0.78,0.81]} & {[0.70,0.77]} & {[0.74,0.78]} \\
{[0.67,0.70]} & {[0.67,0.70]} & {[0.69,0.74]} & {[0.62,0.67]} & {[0.65,0.70]} \\
{[0.61,0.68]} & {[0.70,0.75]} & {[0.88,0.91]} & {[0.79,0.85]} & {[0.79,0.83]} \\
{[0.70,0.76]} & {[0.66,0.71]} & {[0.73,0.77]} & {[0.77,0.80]} & {[0.75,0.80]}
\end{array}\right) \\
& \boldsymbol{u}_{i j}^{3}=\left(\begin{array}{llllll}
{[0.71,0.78]} & {[0.86,0.89]} & {[0.85,0.88]} & {[0.76,0.81]} & {[0.77,0.81]} \\
{[0.69,0.79]} & {[0.79,0.85]} & {[0.71,0.74]} & {[0.72,0.78]} & {[0.76,0.82]} \\
{[0.69,0.74]} & {[0.77,0.83]} & {[0.77,0.82]} & {[0.69,0.78]} & {[0.75,0.79]} \\
{[0.69,0.73]} & {[0.69,0.71]} & {[0.70,0.76]} & {[0.63,0.69]} & {[0.66,0.71]} \\
{[0.62,0.69]} & {[0.68,0.73]} & {[0.90,0.92]} & {[0.81,0.86]} & {[0.80,0.83]} \\
{[0.69,0.73]} & {[0.63,0.68]} & {[0.71,0.75]} & {[0.76,0.81]} & {[0.76,0.81]}
\end{array}\right) \\
& \boldsymbol{u}_{i j}^{4}=\left(\begin{array}{cccccc}
{[0.72,0.78]} & {[0.81,0.87]} & {[0.86,0.89]} & {[0.74,0.79]} & {[0.75,0.82]} \\
{[0.73,0.81]} & {[0.81,0.86]} & {[0.68,0.72]} & {[0.70,0.78]} & {[0.74,0.79]} \\
{[0.66,0.70]} & {[0.76,0.80]} & {[0.79,0.84]} & {[0.74,0.77]} & {[0.72,0.80]} \\
{[0.66,0.71]} & {[0.68,0.73]} & {[0.72,0.75]} & {[0.65,0.70]} & {[0.69,0.75]} \\
{[0.66,0.70]} & {[0.69,0.74]} & {[0.87,0.93]} & {[0.84,0.87]} & {[0.78,0.82]} \\
{[0.68,0.75]} & {[0.64,0.67]} & {[0.69,0.74]} & {[0.78,0.82]} & {[0.78,0.83]}
\end{array}\right) \\
& \boldsymbol{u}_{i j}^{5}=\left(\begin{array}{ccccc}
{[0.73,0.77]} & {[0.87,0.89]} & {[0.82,0.87]} & {[0.71,0.83]} & {[0.76,0.84]} \\
{[0.74,0.80]} & {[0.78,0.84]} & {[0.70,0.76]} & {[0.74,0.79]} & {[0.77,0.80]} \\
{[0.68,0.72]} & {[0.77,0.85]} & {[0.80,0.85]} & {[0.73,0.79]} & {[0.73,0.76]} \\
{[0.69,0.75]} & {[0.67,0.72]} & {[0.68,0.77]} & {[0.63,0.66]} & {[0.68,0.72]} \\
{[0.67,0.72]} & {[0.71,0.75]} & {[0.88,0.94]} & {[0.83,0.88]} & {[0.77,0.85]} \\
{[0.67,0.74]} & {[0.62,0.69]} & {[0.70,0.77]} & {[0.75,0.79]} & {[0.77,0.82]}
\end{array}\right) \text {. }
\end{aligned}
$$

(i) According to (1), take $\rho=0.96$, we can obtain the measure matrix of the consensus partial decision-making program, which is shown as follows:

$\boldsymbol{x}_{i}^{*}=\left[\begin{array}{lllll}0.7507 & 0.8486 & 0.8467 & 0.7776 & 0.7987 \\ 0.7718 & 0.8064 & 0.7104 & 0.7450 & 0.7776 \\ 0.6912 & 0.7834 & 0.7968 & 0.7430 & 0.7488 \\ 0.6970 & 0.6816 & 0.7238 & 0.6528 & 0.6931 \\ 0.6758 & 0.7162 & 0.8870 & 0.8352 & 0.8006 \\ 0.7200 & 0.6605 & 0.7277 & 0.7776 & 0.7872\end{array}\right]$.

(ii) Considering that each DM has a minimum and most willing to accept the evaluation value for all the programs under the index $\boldsymbol{a}_{j}$, which is taken as $d_{10 j}^{0 k}$ and $d_{20 j}^{0 k}$, respectively. According to (2), we can set up the consensus overall ideal decision-making program optimization model, and then, calculate the measure matrix of the consensus overall ideal decision-making program, which is shown as follows:

$\boldsymbol{x}_{0}^{*}=\left[\begin{array}{lllll}0.7718 & 0.8486 & 0.8870 & 0.8352 & 0.8064 \\ 0.7718 & 0.8486 & 0.8870 & 0.8352 & 0.8064 \\ 0.7718 & 0.8486 & 0.8870 & 0.8352 & 0.8064 \\ 0.7718 & 0.8486 & 0.8870 & 0.8352 & 0.8064 \\ 0.7718 & 0.8486 & 0.8870 & 0.8352 & 0.8064 \\ 0.7718 & 0.8486 & 0.8870 & 0.8352 & 0.8064\end{array}\right]$


(iii) According to the models constructed by (3) and (4), taking the resolution coefficient $\lambda=0.5$, the grey incidence degrees can be obtained as follows:

$\boldsymbol{\xi}_{i}=[0.8011,0.6471,0.5479,0.4211,0.7857,0.5460]$.

Then, the ranking of these brands is $x_{1} \succ x_{5} \succ x_{2} \succ$ $x_{3} \succ x_{6} \succ x_{4}$. Based on the results, by comprehensively considering the index information, Lenovo is the most reliable brand on the site, to which customers can give the priority in their purchase.

\subsection{Comparative analysis}

In order to further validate the validity and rationality of the proposed approach, the results based on the models $[18,44-46]$ are obtained. Based on the methods from the literature, the decision results are acquired in Table 1.

Table 1 Comparative analysis

\begin{tabular}{cl}
\hline Literature & Ranking result \\
\hline [18] & $x_{1} \succ x_{5} \succ x_{3} \succ x_{2} \succ x_{6} \succ x_{4}$ \\
[45] & $x_{1} \succ x_{5} \succ x_{2} \succ x_{3} \succ x_{4} \succ x_{6}$ \\
[46] & $x_{1} \succ x_{5} \succ x_{3} \succ x_{2} \succ x_{4} \succ x_{6}$ \\
[47] & $x_{1} \succ x_{5} \succ x_{2} \succ x_{3} \succ x_{6} \succ x_{4}$ \\
Proposed model & $x_{1} \succ x_{5} \succ x_{2} \succ x_{3} \succ x_{6} \succ x_{4}$ \\
\hline
\end{tabular}

By exploiting the method [18], the ranking result is $x_{1} \succ x_{5} \succ x_{3} \succ x_{2} \succ x_{6} \succ x_{4}$, which is significantly different from the ranking of the scheme $x_{2}, x_{3}$ based on the proposed model. They mainly use the feedback control to make the DMs opinions reach a consensus, the feedback and adjustments are made to the experts with inconsistent opinions in the system. This requires first setting a consensus standard, but this standard is not necessarily satisfactory to all experts, and it needs to pay some adjustment costs based on the consensus reached by the feedback. However, in our paper, according to the opinions of all DMs, all the schemes are negotiated to obtain individual consistent schemes, and then coordinated to obtain the overall optimal scheme, which can make all DMs satisfy and have certain superiority. Based on the method [45], the ranking result is $x_{1} \succ x_{5} \succ x_{2} \succ x_{3} \succ x_{4} \succ x_{6}$, which is different from that of this paper. This is mainly because the method [45] ignores the mining of the group behavior information, and subjectively sets the ideal scheme (bull'seye) by taking the maximum values as the group bull's-eye. Using the method [46], we can have the ranking results $x_{1} \succ x_{5} \succ x_{3} \succ x_{2} \succ x_{4} \succ x_{6}$, which is largely different from the ranking of the scheme $x_{2}, x_{3}, x_{4}, x_{6}$ based on the proposed model. Although they can deal with the uncertain and fuzzy information by combing hesitant fuzzy sets with the grey incidence analysis, they do not consider the importance of DMs to the final outcome and choice of options, ignoring the satisfaction and behavior of DMs.

Based on the method [47], the results are obtained as follows: $x_{1} \succ x_{5} \succ x_{2} \succ x_{3} \succ x_{6} \succ x_{4}$, which are the same as those in this paper, but its decision-making steps are too cumbersome and inefficient, and its evaluation accuracy is not high when the DMs' evaluation index is close to the decision-making system. Compared with the group decision-making method [18,45-47], this proposed approach can fully extract the group behavior information and realize the consensus of the partial program and the group program through bargaining, which can avoid the influence of human subjective initiative, and make the decision-making result more stable.

Based on the case analysis, the proposed model can take the existing information to excavate the relevant information and rules in the group decision and deal with the group decision problem properly, so that the evaluation results will be more realistic, which lays the foundation for the effective mining and aggregation of the group decision information.

\section{Conclusions}

To solve the sorting problem of the consensus decision, we exploit the grey incidence analysis and Nash bargaining model to construct a group decision model. Through the model and case analysis, the results show that the proposed approach has the following advantages.

(i) The proposed approach exploits the group behavior characteristics to analyze the differences between group decision and overall decision from the perspectives of group negotiation and system coordination, which can improve the accuracy and applicability of the decisionmaking.

(ii) The proposed approach takes full account of the evaluation information, and effectively excavates the DM information and decision index information in the group decision, and makes the decision problem more appropriate, so that the evaluation results are more realistic, which lays the foundation for the effective mining and aggregation of the group decision information.

However, there are some shortcomings of the proposed approach, which are difficult to deal with the dynamic group decision-making problem effectively. The proposed decision-making approach does not take into account the influence of the time factor, and the established model cannot change over time.

\section{References}

[1] LIU S F, YANG Y J, LIN Y. Grey data analysis: method, models and applications. New York: Springer-Verlag, 2016. 
[2] YAN H B, MA T J. A group decision-making approach to uncertain quality function deployment based on fuzzy preference relation and fuzzy majority. European Journal of Operational Research, 2015, 241(3): 815-829.

[3] SAFARZADEH S, KHANSEFID S, BARZOKI M R. A group multi-criteria decision-making based on best-worst method. Computers \& Industrial Engineering, 2018, 126(2): 111-121.

[4] YAO O Y, WITOLD P. A new model for intuitionistic fuzzy multi-attributes decision making. European Journal of Operational Research, 2016, 249(2): 677-682.

[5] WANG Z J. A note on "A goal programming model for incomplete interval multiplicative preference relations and its application in group decision-making". European Journal of Operational Research, 2015, 247(3): $867-871$.

[6] WAN S P, LI S Q, DONG J Y. A three-phase method for Pythagorean fuzzy multi-attribute group decision making and application to haze management. Computers \& Industrial Engineering, 2018, 123(9): 348-363.

[7] XU Y J, WEN X W, ZHANG W C. A two-stage consensus method for large-scale multi-attribute group decision making with an application to earthquake shelter selection. Computers \& Industrial Engineering, 2018, 116(2): 113-129.

[8] WAN S P, WANG F, DONG J Y. Additive consistent intervalvalued Atanassov intuitionistic fuzzy preference relation and likelihood comparison algorithm based group decision making. European Journal of Operational Research, 2017, 263(2): $571-582$.

[9] QIN J D, LIU X W, PEDRYCZ W. An extended TODIM multicriteria group decision making method for green supplier selection in interval type-2 fuzzy environment. European Journal of Operational Research, 2017, 258(2): 626-638.

[10] WU Q, LIN W H, ZHOU L G, et al. Enhancing multiple attribute group decision making flexibility based on information fusion technique and hesitant Pythagorean fuzzy sets. Computers \& Industrial Engineering, 2019, 127(1): 954-970.

[11] KUMAR S, JOSHI D. Fuzzy ideal based computational approach for group decision making problems. Fuzzy Information and Engineering, 2017, 9(2): 247-258.

[12] DEEPA J, KUMAR S. Interval-valued intuitionistic hesitant fuzzy Choquet integral based TOPSIS method for multicriteria group decision making. European Journal of Operational Research, 2016, 248(1): 183-191.

[13] BRÄUNING M, HÜLLERMEIER E, KELLER T, et al. Lexicographic preferences for predictive modeling of human decision making: a new machine learning method with an application in accounting. European Journal of Operational Research, 2017, 258(1): 295 - 306.

[14] SUN B Z, MA W M, CHEN X T. Variable precision multigranulation rough fuzzy set approach to multiple attribute group decision-making based on $\lambda$-similarity relation. Computers \& Industrial Engineering, 2018, 126(12): 345 - 355.

[15] LIU J P, LIAO X W, YANG J B. A group decision-making approach based on evidential reasoning for multiple criteria sorting problem with uncertainty. European Journal of Operational Research, 2015, 246(3): 858-873.

[16] MA L C. A new group ranking approach for ordinal preferences based on group maximum consensus sequences. European Journal of Operational Research, 2016, 251(1): $171-$ 181.

[17] DONG Q X, COOPER O. A peer-to-peer dynamic adaptive consensus reaching model for the group AHP decision making. European Journal of Operational Research, 2016, 250(2): $521-530$

[18] WU J, SUN Q, FUJITA H, et al. An attitudinal consensus degree to control the feedback mechanism in group decision making with different adjustment cost. Knowledge-Based Systems, 2019, 164(1): 265-273.

[19] ZHANG H J, DONG Y C, CHICLANA F, et al. Consensus efficiency in group decision making: a comprehensive comparative study and its optimal design. European Journal of Operational Research, 2019, 275(2): 580-598.

[20] DONG Y C, ZHA Q B, ZHANG H J, et al. Consensus reaching in social network group decision making: research paradigms and challenges. Knowledge-Based Systems, 2018, 162(12): $3-13$.

[21] CHENG L C, CHEN Y L, CHIANG Y C. Identifying conflict patterns to reach a consensus - a novel group decision approach. European Journal of Operational Research, 2016, 254(2): 622-631.

[22] PÉREZ I J, CABRERIZO F J, ALONSO S, et al. On dynamic consensus processes in group decision making problems. Information Sciences, 2018, 459(8): 20-35.

[23] LIU J P, LIAO X W, HUANG W, et al. A new decision-making approach for multiple criteria sorting with an imbalanced set of assignment examples. European Journal of Operational Research, 2018, 265(2): 598-620.

[24] SMRITHI R V, HENRY M. Group decision-making in software architecture: a study on industrial practices. Information and Software Technology, 2018, 101: 51-63.

[25] MANISH AGGARWAL. Hesitant information sets and application in group decision making. Applied Soft Computing Journal, 2019, 75(2): 120-129.

[26] ABTEEN I M, MOJAN M, ASHKAN H, et al. Hybrid hierarchical fuzzy group decision-making based on information axioms and BWM: prototype design selection. Computers \& Industrial Engineering, 2019, 127(1): 788 - 804.

[27] LIU Y, FAN Z P, YOU T H, et al. Large group decision-making (LGDM) with the participators from multiple subgroups of stakeholders: a method considering both the collective evaluation and the fairness of the alternative. Computers \& Industrial Engineering, 2018, 122(8): 262-272.

[28] FU C, CHANG W J, XUE M, et al. Multiple criteria group decision making with belief distributions and distributed preference relations. European Journal of Operational Research, 2019, 273(2): 623-633.

[29] KIMURA K, SAWADAB H, KATAYAMA J. Outcome evaluations in group decision making using authority rule: an electrophysiological study. Neuro Psychologia, 2018, 119: 271-279.

[30] MERIGÓ J M, MARQUÉS D P, ZENG S Z. Subjective and objective information in linguistic multi-criteria group decision making. European Journal of Operational Research, 2016, 248(2): $522-531$.

[31] GAO Q, CHEN X, LI Z Z. The influence of the shared-display configuration on group decision making. International Journal of Industrial Ergonomics, 2016, 51(2): 59-67.

[32] RAJESH R, RAVI V. Supplier selection in resilient supply chains: a grey relational analysis approach. Journal of Cleaner Production, 2015, 86(1): 343-359.

[33] WANG P, ZHUA Z Q, WANG Y H. A novel hybrid MCDM model combining the SAW, TOPSIS and GRA methods based on experimental design. Information Sciences, 2016, 345(6): $27-45$.

[34] ZHU J J, ZHANG S T, CHEN Y, el al. A hierarchical clustering approach based on three-dimensional gray relational analysis for clustering a large group of decision makers with double information. Group Decision and Negotiation, 2016, 25(2): $325-354$.

[35] HASHEMI A H, KARIMI A, TAVANA M. An integrated green supplier selection approach with analytic network process and improved grey relational analysis. International Jour- 
nal of Production Economics, 2015, 159(1): 178-191.

[36] TANG H X. A novel fuzzy soft set approach in decision making based on grey relational analysis and Dempster-Shafer theory of evidence. Applied Soft Computing, 2015, 31(6): $317-325$.

[37] LI P, LIU J, LIU S F, et al. Grey target method for intuitionistic fuzzy decision making based on grey incidence analysis. The Journal of Grey System, 2016, 28(4): 96-109.

[38] WANG H H, ZHU J J, FANG Z G. Aggregation of multi-stage linguistic evaluation information based on grey incidence degree. Control and Decision, 2013, 28(1): 109-114. (in Chinese)

[39] YAN S L, LIU S F, LIU J F, et al. Dynamic grey target decision making method with grey numbers based on existing state and future development trend of alternatives. Journal of Intelligent \& Fuzzy Systems, 2015, 28(5): 2159-2168.

[40] LIU Y, FORREST J, LIU S F. Dynamic grey incidence group decision making methodology based on interval two-tuple linguistic information processing and application. Systems Engineering and Electronics, 2013, 35(9): 1915-1922. (in Chinese)

[41] LIU H C, LI P, YOU J X, et al. A novel approach for FMEA: combination of interval 2-tuple linguistic variables and gray relational analysis. Quality and Reliability Engineering International, 2015, 31(5): 761 - 772. (in Chinese)

[42] WANG H H, ZHU J J, FANG Z G. Group aggregation method on large-scale linguistic evaluation information based on grey cluster. Control and Decision, 2012, 27(2): 271 - 280. (in Chinese)

[43] MANZARDO A, REN J Z, MAZZI A, et al. A grey-based group decision-making methodology for the selection of hydrogen technologies in life cycle sustainability perspective. International Journal of Hydrogen Energy, 2012, 37(23): $17663-17670$.

[44] WINSTON W L. Operations research application and algorithms. Beijing: Tsinghua University Press, 2006. (in Chinese)

[45] SAMVEDIA A, JAINA V, CHAN F T S. An integrated approach for machine tool selection using fuzzy analytical hierarchy process and grey relational analysis. International Journal of Production Research, 2012, 50(12): 3211 - 3221.
[46] SUN G D, GUAN X, YI X, et al. Grey relational analysis between hesitant fuzzy sets with applications to pattern recognition. Expert Systems with Applications, 2018, 92(3): $521-$ 532.

[47] WU Z, XU J. A concise consensus support model for group decision making with reciprocal preference relations based on deviation measures. Fuzzy Sets \& Systems, 2012, 206(11): $58-73$.

\section{Biographies}

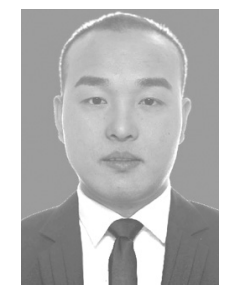

LIU Yong was born in 1985. He received his B.S., M.S., and Ph.D. degrees in mechanical engineering, and system engineering and management science and engineering from Nanjing University of Aeronautics and Astronautics. Currently, he is an associate professor in Jiangnan University. His research interests include conflict analysis, soft computing, and grey system.

E-mail: clly1985528@163.com

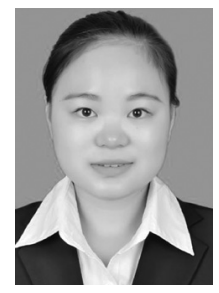

LI Jiao was born in 1994. She received her B.S. degree in logistics management from Yangtze University. Currently, she is a graduate student in School of Business, Jiangnan University. Her research interests include conflict coordination, incentive mechanism of supply chain channel and grey system.

E-mail: 930229529@qq.com

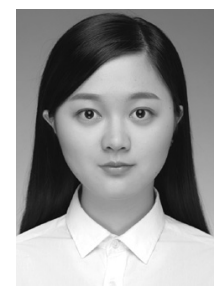

ZHANG Renshi was born in 1998. Currently, she is a senior student in School of Business, Jiangnan University. Her research interests include uncertainly prediction and decision making.

E-mail: 6180903007@stu.jiangnan.edu.cn 